7. Reprod. Fert. (1975) 42, 407-414

\title{
PLASMA PROGESTERONE CONCENTRATIONS IN PRAIRIE DEERMICE (PEROMYSCUS MANICULATUS BAIRDII) FROM EXPERIMENTAL LABORATORY POPULATIONS
}

\author{
B. D. ALBERTSON, ${ }^{*}$ E. L. BRADLEY $\dagger$ AND C. R. TERMAN $\dagger$ \\ Laboratory of Endocrinology and Population Ecology, Biology Department, \\ College of William and Mary, Williamsburg, Virginia 23185, U.S.A.
}

(Received 4th February 1974)

\begin{abstract}
Summary. Body weights, ovary weights, plasma progesterone concentrations and ovarian histology were studied in females from asymptotic laboratory populations in which reproduction was inhibited and throughout the oestrous cycle of control nulliparous prairie deermice. Body and ovary weights of population animals were significantly lighter and plasma progesterone concentrations were not significantly different from those of the control females. The control females exhibited cyclic changes in plasma progesterone concentration that were related to the oestrous cycle. The mean plasma progesterone concentration for the nulliparous 'population' females was significantly above the pro-oestrous, and below the metoestrous values of 'control' females, but was not significantly different from values observed at oestrus or dioestrus. The ovaries of 'control' females had significantly larger numbers of follicles and corpora lutea than nulliparous 'population' females but the latter had significantly more atretic follicles.
\end{abstract}

\section{INTRODUCTION}

Numerical studies of natural populations of deermice (Peromyscus maniculatus) have shown that population outbreaks of this species rarely occur (Christian, 1961; Terman, 1965). The evidence available suggests that deermice may be more sensitive to density-dependent factors that limit population increase, and may possess a more efficient mechanism for controlling population growth than do species such as Lemmus, Microtus and Mus for which extreme fluctuations in numbers occur (Terman, 1966).

Studies of experimental laboratory populations of prairie deermice (Peromyscus maniculatus bairdii) have demonstrated that population growth was controlled under conditions in which excess food, water and shelter were available. Cessation of growth occurred at widely different levels in populations

\footnotetext{
* Present address: Boston University, Department of Biology, 2 Cummington St, Boston, Massachusetts 02215, U.S.A.

$\uparrow$ Reprint requests to Dr E. L. Bradley or Dr C. R. Terman.
} 
maintained under identical conditions of the physical environment, and was achieved by one of two means: either through failure of the young to survive or by cessation of reproduction (Terman, 1965, 1969, 1973). These data suggest that a density-related feedback mechanism exists to control population by curbing reproduction, perhaps involving the hypothalamic-hypophysialgonadal axis (Christian, 1963, 1964; Christian \& Davis, 1964; Christian, Lloyd \& Davis, 1965; Terman, 1969).

In the present experiment, plasma progesterone concentrations and ovarian histology in normal cyclic deermice and in nulliparous females from the experimental populations were examined to determine if progesterone concentration is a central factor in, or is correlated with, a neuroendocrine mechanism producing inhibition of reproduction.

\section{MATERIALS AND METHODS}

The 'population' and the 'control' animals were maintained under an artificia light regimen of approximately $12 \mathrm{hr}$ bright light (four $40 \mathrm{~W}$ fluorescent tubes), 07.30 to 19.30 hours, followed by $15 \mathrm{~min}$ darkness and then $11 \frac{3}{4} \mathrm{hr}$ dim light (four $15 \mathrm{~W}$ incandescent bulbs). Room temperatures were kept within a range of $21^{\circ}$ to $30^{\circ} \mathrm{C}$. Food and water were freely available.

\section{'Population' animals}

The experimental populations were founded by four pairs of prairie deermice (Peromyscus maniculatus bairdii) from eight different litters (60 to 100 days of age) with the female of each pair being pregnant. The first litter of each pregnant female was killed 21 days after birth. The second, and successive, litters were conceived in the population and remained part of it. Five of the ten populations used in this study had reached asymptote (Terman, 1965), and young had not been born into these five populations for a minimum of 116 days. The other five populations had not reached asymptote when all their members were killed, but they included nulliparous daughters which could be compared with females in the asymptotic populations. The nulliparous females from the experimental populations were 94 to 486 days of age and $86 \%$ did not have a perforated vagina at autopsy.

\section{'Control' animals}

Adult female deermice were paired with non-sibling males of the same age (a minimum of 60 days) in cages $(12 \times 26 \times 14 \mathrm{~cm})$ which allowed visual, olfactory and auditory cues from the male, but prevented contact by means of a partition of two layers of hardware cloth $2 \mathrm{~cm}$ apart. Two groups of control females were used. Group I consisted of thirty-five females in which the stage of the oestrous cycle was determined by daily vaginal lavage, and fifty females that were never so examined. Group II consisted of fifty females, all of which were examined for oestrous cycles by vaginal lavage. All the control females were housed in the partitioned cages with males for at least 21 days before vaginal 
lavage was begun and for at least 35 days before autopsy. At autopsy, deermice in Groups I and II were 130 to 338 days and 108 to 135 days of age, respectively.

\section{Tissue collection}

Animals were rapidly anaesthetized with the minimum quantity of ether. Blood was obtained between 13.00 and 16.00 hours from 'control' and 'population' females by venepuncture of the ascending vena cava at the level of the renal vein using a heparinized syringe. The total time for collection of a blood sample did not exceed $2 \mathrm{~min}$. The samples were immediately centrifuged at $1000 \mathrm{~g}$ for $15 \mathrm{~min}$. The plasma was drawn off, and frozen at $-20^{\circ}$ until assayed. The whole animal was then placed in $10 \%$ formalin. Later, ovaries were removed from the carcases, cleaned of fat, lightly blotted and weighed as paired organs to the nearest $0.01 \mathrm{mg}$.

\section{Plasma progesterone concentration}

The steroids used, $\left[1 \alpha, 2 \alpha_{-}{ }^{3} \mathrm{H}\right]$ progesterone (Amersham/Searle, sp. act. $=53$ $\mathrm{Ci} / \mathrm{mmol}$ ) and non-radioactive progesterone (Schwarz/Mann), were checked for purity by thin-layer chromatography. Before use, precoated thin-layer plates (Silica Gel 60 F-254, E. M. Laboratories, Inc.) were washed twice by ascending chromatography with methanol and then once with absolute diethyl ether. Binding protein plasma was obtained by cardiac puncture from pregnant albino guinea-pigs in the last part of gestation, and stored in $0.1 \mathrm{ml}$ quantities at $-20^{\circ} \mathrm{C}$.

Plasma progesterone concentrations were determined according to the method outlined by Tullner $\&$ Hopper (1970), except that $200 \mu$ l plasma were extracted and corticosteroid-binding globulin was prepared from pregnant guinea-pig plasma according to the method of Attal \& Engels (1971).

\section{Histology}

Ovaries, from control deermice at various stages of oestrus and from nulliparous 'population' females from four populations, were embedded in paraffin wax, serially sectioned at $10 \mu \mathrm{m}$ and stained with haematoxylin and eosin. The ovaries were examined under $\times 80$ magnification. The total numbers of follicles of type $5 \mathrm{a}$, or larger (Pedersen \& Peters, 1968) and corpora lutea were counted for both ovaries of each deermouse. Follicles were classified as atretic if they were ovoid or irregular in shape and filled with a non-cellular matrix. The number of atretic follicles in the most central section of the middle row and one of those on either side were counted, and the mean number per section for both ovaries of each deermouse was recorded.

\section{Statistical analysis}

Comparisons of body weights, ovary weights and plasma progesterone concentrations were made using the means of the experimental populations because the individuals within each experimental population are not statistically independent. The data were subjected to linear correlation coefficient analysis and Student's $t$ test. When significant differences $(P<0.05)$ between the mean squares occurred, Cochran's approximation was used (Snedecor, 1956). 


\section{RESULTS}

The oestrous cycle of 'control' females

The length of the oestrous cycle was calculated for forty-two animals that had been followed through at least two full cycles. The deermouse cycle ranged from 3 to 7 days, with a mean of $4 \cdot 7 \pm 0 \cdot 15$ (S.E.M.) days. No significant differences between control Groups I and II were observed, and the data from the two groups were, therefore, pooled for each stage of the oestrous cycle. Significant differences in plasma progesterone concentrations were observed at

Table 1. Comparisons of plasma progesterone concentrations throughout the oestrous cycle of 'control' deermice and of 'population' nulliparous females

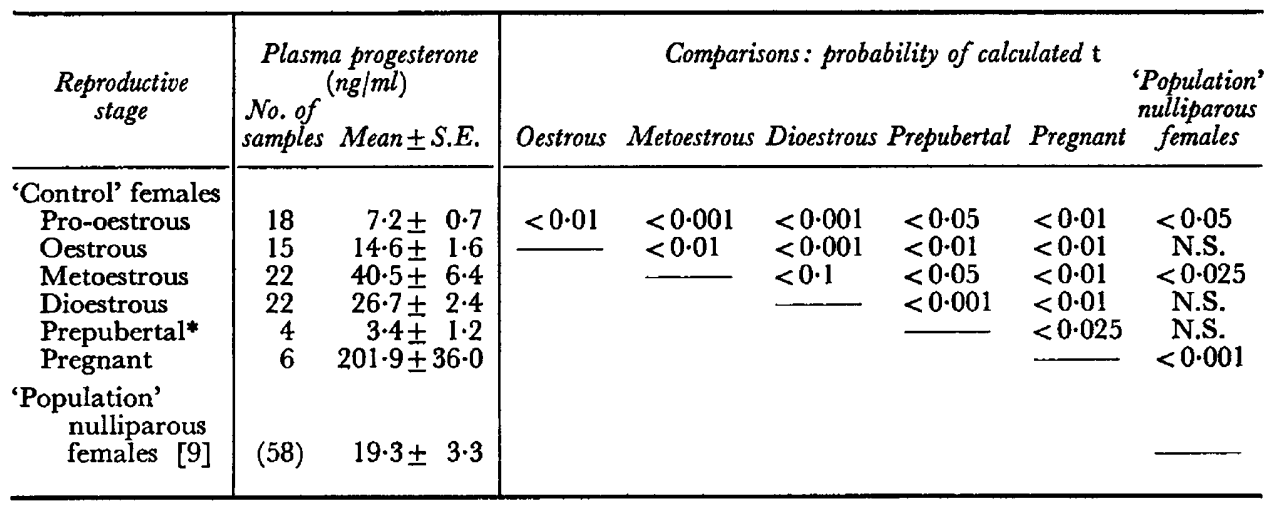

Number in brackets refers to the number of experimental populations. Number in parentheses refers to the total number of individuals in the population.

* The vagina had not become perforate in these deermice.

Table 2. Comparison of the body weights, ovary weights and plasma progesterone levels in 'population' and 'control' deermice

\begin{tabular}{|c|c|c|c|c|c|c|}
\hline & $\begin{array}{l}\text { Bod } \\
\text { No. of } \\
\text { animals }\end{array}$ & $\begin{array}{l}\text { weight }(g) \\
\text { Mean } \pm S . E .\end{array}$ & $\begin{array}{l}\text { Wto } \\
\text { No. of } \\
\text { animals }\end{array}$ & $\begin{array}{l}\text { both ovaries } \\
\qquad \text { Mean } \pm \text { S.E. }\end{array}$ & $\begin{array}{l}\text { Plasma pr } \\
\text { No. of } \\
\text { animals }\end{array}$ & $\begin{array}{c}\text { rogesterone }(n g / m l) \\
\text { Mean } \pm \text { S.E. }\end{array}$ \\
\hline $\begin{array}{l}\text { 'Control' females } \\
\text { Nulliparous } \\
\text { 'population' females }\end{array}$ & $\begin{array}{c}90 \\
{[9](59)}\end{array}$ & $\begin{array}{l}17 \cdot 8 \pm 0.33 \\
12 \cdot 6 \pm 0.36^{* *}\end{array}$ & $\begin{array}{c}90 \\
{[9](59)}\end{array}$ & $\begin{array}{l}16 \cdot 37 \pm 0.78 \\
5 \cdot 14 \pm 0.42^{* *}\end{array}$ & $\begin{array}{c}90 \\
{[9](58)}\end{array}$ & $\begin{array}{l}23 \cdot 1 \pm 2 \cdot 60 \\
19 \cdot 3 \pm 3 \cdot 37^{\text {N.s. }}\end{array}$ \\
\hline
\end{tabular}

** $P<0.001 ;$ N.S. = not significant at $P<0.1$. Numbers in brackets refer to the numbers of experimental populations. Numbers in parentheses refer to total numbers of individuals in the populations.

all stages of the cycle (Table 1). A $103 \%$ increase $(P<0.01)$ in the mean progesterone concentration was observed from pro-oestrus to oestrus, and a $177 \%$ increase $(P<0.01)$ occurred from oestrus to metoestrus. A decrease of the mean progesterone concentration $(P<0 \cdot 1)$ by $52 \%$ occurred from metoestrus to dioestrus.

Four control females failed to exhibit vaginal perforation, and the mean progesterone concentration of these females was significantly lower than those levels noted for all stages of the oestrous cycle (Table 1). 
The mean progesterone concentration in six pregnant deermice was significantly greater than that for any stage of the oestrous cycle of 'control' females (Table 1).

\section{Comparisons of 'control' and 'population' females}

Body and ovary weights. Nulliparous deermice from the experimental populations had significantly lower mean body weights $(P<0.001)$ and significantly smaller mean ovary weights $(P<0 \cdot 001)$ than 'control' females (Table 2$)$.

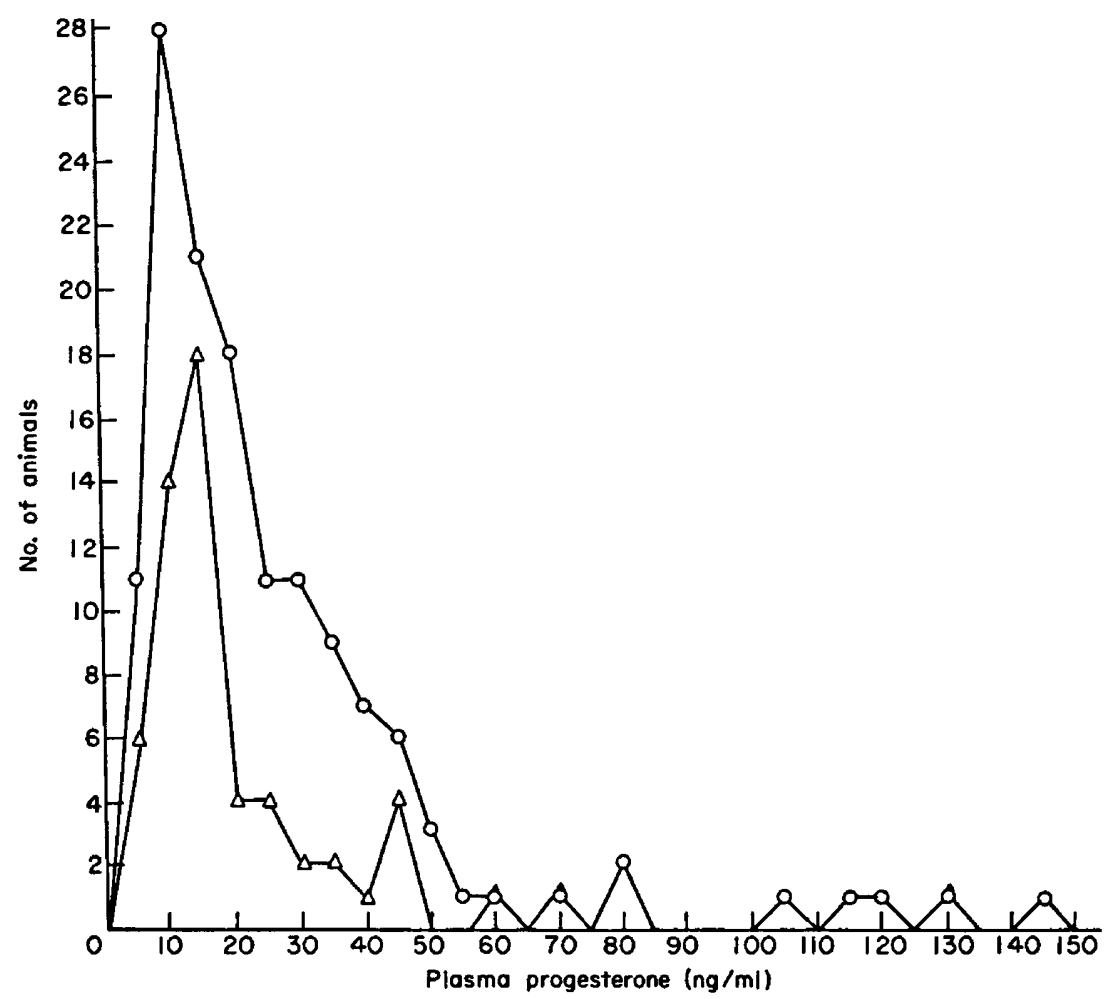

Text-Fig. 1. The frequency distribution of plasma progesterone concentrations of 'control' $(O)$ and nulliparous 'population' $(\Delta)$ deermice.

Plasma progesterone. Text-figure 1 shows the frequency distribution of the progesterone levels of 'control' and 'population' females. No significant differences in the mean progesterone concentrations were observed (Table 2). No significant correlation was demonstrated between ovary weights and plasma progesterone concentrations of 'control' females, but there was a significant positive correlation $(r=3.51) \quad(P<0.01)$ for nulliparous 'population' females. As shown in Table 1, 'control' females had significantly lower $(P<0.05)$ mean concentrations of progesterone at pro-oestrus, and significantly higher $(P<0.025)$ mean concentrations at metoestrus than 'population' females.

Ovarian histology. Nulliparous 'population' females had significantly fewer follicles of type $5 \mathrm{a}$ or larger $(P<0.001)$ and fewer corpora lutea $(P<0.001)$ than 
'control' females but they had more $(P<0.05)$ atretic follicles. No correlation could be demonstrated between progesterone concentrations and numbers of follicles, corpora lutea or atretic follicles in 'control' or nulliparous 'population' females.

\section{DISCUSSION}

The data obtained in this study have shown that circulating plasma progesterone concentrations in control female prairie deermice fluctuate in a pattern similar to that found in other spontaneously ovulating mammals. Mean plasma progesterone concentrations increased from pro-oestrus to oestrus, reached their highest levels at metoestrus, and then declined in dioestrus. The mean progesterone concentrations in the deermouse were similar to those reported for the golden hamster (Lukaszewska \& Greenwald, 1969).

Four of the 'control' females did not have a perforate vagina, indicating that they had not reached puberty. The mean progesterone concentrations measured in these females were approximately half the value observed in the other 'control' females at pro-oestrus.

The significantly smaller mean body and ovary weights in nulliparous 'population' females suggest a possible inhibition of both total body development and reproductive maturation, although significant differences in body weight have not been demonstrated in previous studies (Terman, 1969). It is possible, therefore, that the differences in body weight may have been due to some other factors in the present experiments. The 'control' animals had large amounts of subcutaneous and mesenteric fat at autopsy, indicating overeating and insufficient activity. Progesterone concentrations can be correlated with numbers of corpora lutea in sheep (Thorburn, Bassett \& Smith, 1969). There was a significant positive correlation $(P<0.01)$ between ovary weights and plasma progesterone concentrations only for the nulliparous 'population' females. When the healthy and atretic follicles and corpora lutea were counted, however, and each was compared with the progesterone concentrations in 'control' and nulliparous 'population' deermice, no significant correlations were found. Corpora lutea and follicles were observed in all 'control' females, but some 'population' females had no corpora lutea and high progesterone concentrations. It is possible that this progesterone was secreted from other sources, such as the stroma or interstitium of the ovary (Lukaszewska \& Greenwald, 1969), the adrenal (Feder, Resko \& Goy, 1968; Piva, Gagliano, Motta \& Martini, 1973). Adrenal progesterone, in conjunction with oestrogens, may be required to facilitate the pro-oestrous surge of LH in the rat (Mann \& Barraclough, 1973). Further investigations into the nature of the secretory products of the atretic follicles, which are characteristic of the 'population' females, the ovarian stroma and adrenal cortex may prove to be important in understanding the endocrinology of the animals in which reproduction was inhibited.

We have not demonstrated a chronic level of progesterone that might interfere with the secretion of gonadotrophins and, thereby, ovulation. Progesterone can exert both facilitatory and inhibitory effects on mating behaviour 
and the time of ovulation in the rat (Stevens, Spies, Hilliard \& Sawyer, 1970; Barraclough, Collu, Massa \& Martini, 1971; Lawton, 1972) and in the golden hamster (Lisk, 1969; Reuter, Ciaccio \& Lisk, 1970). It is possible that the 'population' deermice are inhibited only to a degree and that all the elements of reproductive potential are present but are operating at subnormal levels or out of phase.

The variation observed in the plasma progesterone concentrations among nulliparous 'population' females could be explained by at least two very different hypotheses. The first of these is that most of the inhibited females would have shown a cyclic variation in plasma progesterone concentration if several plasma samples could have been taken from them at various times. The fact that the range of progesterone concentrations of 'population' and 'control' females overlap almost exactly and that $90 \%$ of the females of both groups had less than $45 \mathrm{ng}$ progesterone/ml plasma, mostly between 5 and $15 \mathrm{ng} / \mathrm{ml}$, supports this idea (Text-fig. 1). In the four experimental populations examined, all stages of follicular development, although significantly fewer in number, were observed among the inhibited females, and $77 \%$ of the ovaries contained corpora lutea. If it is assumed that the corpora lutea are evidence of ovulation rather than being luteinized unovulated follicles, then it is likely that FSH and LH were also being released in sufficient amounts to cause ovulation (Bingel \& Schwartz, 1969a, b; Labhsetwar, 1972), and there is no total inhibition of reproductive function in nulliparous 'population' females.

The alternative explanation of these data, which cannot be ruled out due to our inability to collect sequential samples from the same animals, is that the variance observed in ovarian histology and plasma progesterone concentration of nulliparous 'population' animals is not due to cyclic changes within individual animals, but to the animals being in different states of arrested reproductive function. Thus, the presence of corpora lutea in nulliparous 'population' animals may not be indicative of ovulation having occurred within the previous 4 days but could be the result of ovulation having occurred many weeks earlier or the luteinization of unovulated follicles. The progesterone values for individual animals would, therefore, be chronically high, or low, rather than representing different points in a random sample of cyclic animals. The observation that $86 \%$ of the nulliparous 'population' animals did not have a perforate vagina lends further support to the notion that, at least with respect to oestrogen, these animals were not cycling.

If this latter explanation is true, then several states of inhibition may exist among nulliparous females suggesting multiple stages of a single mechanism of inhibition or possibly more than a single mechanism. Terman (1973) found that $75 \%$ of the nulliparous females in which reproduction was inhibited produced litters within 90 days when they were removed from their populations and paired with proven males. Only $23 \%$ of these females, however, reproduced within 30 days of pairing. In the context of the present experiment, these data clearly indicate that, whatever the mechanisms of reproductive inhibition, they are not irreversible and that a period of adjustment or maturation, possibly behavioural as well as physiological, is required before reproduction can take place. 
This study was partly supported by Public Health Service Research Grant HD-04787 and NIH Research Career Development Award HD-07391.

\section{REFERENGES}

Attal, J. \& Engels, J. A. (1971) A simple technique for the assay of progesterone in pregnancy. 7. Endocr. 50, 703-704.

Barraclovgh, C. A., Gollu, R., MAsSA, R. \& Martini, L. (1971) Temporal interrelationships between plasma $L H$, ovarian secretion rates and peripheral plasma progestin concentrations in the rat: effects of nembutal and exogenous gonadotropins. Endocrinology, 88, 1437-1447.

Bingel, A. S. \& Schwartz, N. B. (1969a) Pituitary LH content and reproductive tract changes during the mouse oestrous cycle. F. Reprod. Fert. 19, 215-222.

Bingel, A. S. \& Schwartz, N. B. (1969b) Timing of LH release and ovulation in the cyclic mouse. F. Reprod. Fert. 19, 223-229.

Ghristran, J. J. (1961) Phenomena associated with population density. Proc. natn. Acad. Sci. U.S.A. 47, $428-449$.

Christian, J. J. (1963) Endocrine adaptive mechanisms and the physiologic regulation of population growth. In Physiological Mammalogy, pp. 189-353. Eds. W. V. Mayer and R. G. Van Gelder. Academic Press, New York.

Christian, J. J. (1964) Physiological and pathological correlates of population density. Proc. R. Soc. Med. 57, 169-174.

Christian, J. J. \& Davis, D. E. (1964) Endocrines, behavior and population. Science, N.Y. 146, 11501560 .

Ghristian, J. J., Lloyd, J. A. \& Davis, D. E. (1965) The role of endocrines in the self regulation of mammalian populations. Recent Prog. Horm. Res. 21, 501-578.

Feder, H. H., Resxo, J. A. \& Goy, R. W. (1968) Progesterone levels in the arterial plasma of preovulatory and ovarectomized rats. F. Endocr. 41, 563-569.

LABHSETWAR, A. P. (1972) Further evidence for synergism between LH and FSH in the induction of ovulation in rats; lack of effects of prolactin. 7. Reprod. Fert. 29, 435-438.

LAwTon, I. E. (1972) Facilitatory feedback effects of adrenal and ovarian hormones on LH secretion. Endocrinology, 90, 575-579.

Lisk, R. D. (1969) Progesterone: role in limitation of ovulation and sex behavior in mammals. Trans. N.Y. Acad. Sci. 31, 593-601.

Lukaszewska, J. H. \& Greenwald, G. S. (1969) Progesterone levels in the cyclic and pregnant hamster. Endocrinology, 86, 1-9.

MANN, D. R. \& BARRAclough, G. A. (1973) Role of estrogen and progesterone in facilitating LH release in 4-day cyclic rats. Endocrinology, 93, 694-699.

Pedersen, T. \& Peters, H. (1968) Proposal for a classification of oocytes and follicles in the mouse ovary. F. Reprod. Fert. 17, 555-557.

Piva, F., Gagliano, P., Motta, M. \& Martini, L. (1973) Adrenal progesterone: factors controlling its secretion. Endocrinology, 93, 1178-1184.

Reuter, L. A., Giaccio, L. A. \& Lisk, R. D. (1970) Progesterone: regulation of the estrous cycle, ovulation and estrous behavior in the golden hamster. Endocrinology, 86, 1287-1297.

SNedecor, G. W. (1956) Statistical Methods. Iowa State University Press, Ames, Iowa.

Stevens, K. R., Spies, H. G., Hilliard, J. \& Sawyer, C. H. (1970) Site(s) of action of progesterone in blocking ovulation in the rat. Endocrinology, 86, 970-975.

Thorburn, G. D., BassetT, J. M. \& Smrth, I. D. (1969) Progesterone concentration in the peripheral plasma of sheep during the oestrous cycle. $\mathcal{F}$. Endocr. 45, 459-469.

TERMAN, C. R. (1965) A study of population growth and control exhibited in the laboratory by prairie deermice. Ecology, 46, 890-895.

Terman, G. R. (1966) Population fluctuations of Peromyscus maniculatus and other small mammals as revealed by the North American Gensus of Small Mammals. Am. Midl. Nat. 76, 419-426.

Terman, C. R. (1969) Weights of selected organs of deermice (Peromyscus maniculatus bairdii) from asymptotic laboratory populations. F. Mammal. 50, 311-320.

Terman, G. R. (1973) Reproductive inhibition in asymptotic populations of prairie deermice. F. Reprod. Fert., Suppl. 19, 455-461.

TullNer, W. W. \& Hopper, B. (1970) Urinary estrone and plasma progesterone levels during the menstrual cycle of the rhesus monkey. Endocrinology, 86, 1125-1230. 